\title{
Elementos intervenientes na tomada de decisão
}

\author{
Maria Terezinha Angeloni \\ Professora doutora do Departamento e Curso de Pós-Graduação em \\ Administração da Universidade Federal de Santa Catarina. Coordena- \\ dora do Núcleo de Estudos em Gestão da Informação, do Conheci- \\ mento e da Tecnologia. \\ E-mail: angelggc@terra.com.br
}

"A pesquisa no campo das ciências humanas vive uma crise evidente. Entre as causas a serem destacadas vamos encontrar o desenvolvimento tecnológico acelerado que, aliado a fatores políticos e sociais, leva a empresa a viver uma nova situação. Para ser eficiente, ela agora precisa lidar com informações que até pouco tempo atrás não eram tão importantes."

(Gutierrez, 1999)

\section{Resumo}

Este artigo tem por objetivo analisar os elementos intervenientes na tomada de decisão nas organizações. Trata-se de um estudo teórico que aborda a inter-relação de dado, informação, conhecimento, comunicação e tecnologia da informação como suporte à tomada de decisão. Considerando que não existe uma forma perfeita para a decisão, buscamos seu aperfeiçoamento com a valorização dos bens intangíveis inerentes à sociedade pós-industrial.

Palavras-chave

Informação; Conhecimento; Comunicação; Tecnologia; Decisão.

\section{Intervening elements in decision making}

\begin{abstract}
The purpose of this article is to analyze the elements that intervene in decision making in organizations. This is a theoretical study describing the interrelations of data, information, knowledge, communication and technology as elements of support for decision making. Considering that there is not a perfect pattern for decision making, we sought to improve decision making through valuing inherited intangible goods of the post-industrial society.
\end{abstract}

\section{Keywords}

Information; Knowledge; Communication; Technology; Decision.

\section{INTRODUÇÃO}

As organizações gerenciadas nos moldes taylorianos estão cada vez mais cedendo espaço a novas formas de gestão. $\mathrm{O}$ foco nos bens tangíveis cede lugar a outros bens, os intangíveis. Dos bens intangíveis relevantes para o gerenciamento das organizações, destacamos nesse trabalho o dado, a informação e o conhecimento como subsídios essenciais à comunicação e à tomada de decisão. Para que as decisões organizacionais sejam tomadas com rapidez e qualidade, é importante que as organizações disponham de um sistema de comunicação eficiente, que permita a rápida circulação da informação e do conhecimento, sendo, para isso, indispensável o suporte da tecnologia.

Uma vez que os elementos dado, informação, conhecimento, comunicação e tecnologia dão suporte à tomada de decisão, apresentamos um estudo que visa a analisar suas inter-relações, mas não antes de compreender o significado de cada um deles.

\section{COMPREENDENDO OS TERMOS PARA DISCUTIR O TEMA}

Dado, informação e conhecimento são elementos fundamentais para a comunicação e a tomada de decisão nas organizações, mas seus significados não são tão evidentes. Eles formam um sistema hierárquico de difícil delimitação. O que é um dado para um indivíduo pode ser informação e/ou conhecimento para outro. Davenport (1998) corrobora esse ponto de vista colocando resistência em fazer essa distinção, por considerá-la nitidamente imprecisa. 
Considerando a inter-relação e a difícil possibilidade de separar nitidamente o que é dado, informação e conhecimento, e consciente de sua importância para a decisão, buscamos nesta seção balizar os seus significados no escopo do presente estudo.

Os dados são elementos brutos, sem significado, desvinculados da realidade. São, segundo Davenport (1998, p. 19), "observações sobre o estado do mundo". São símbolos e imagens que não dissipam nossas incertezas. Eles constituem a matéria-prima da informação. Dados sem qualidade levam a informações e decisões da mesma natureza.

Sendo o dado considerado a matéria-prima para a informação: o que são informações?

As informações são dados com significado. "São dados dotados de relevância e propósito" (Drucker apud Davenport, 1998, p.18). Elas são o resultado do encontro de uma situação de decisão com um conjunto de dados, ou seja, são dados contextualizados que visam a fornecer uma solução para determinada situação de decisão (MacDonough apud Lussato, 1991).

A informação pode assim ser considerada como dados processados e contextualizados, mas para Sveiby (1998) a informação também é considerada como "desprovida de significado e de pouco valor”, e Malhotra (1993) a considera como "a matéria-prima para se obter conhecimento".

Mas o que é conhecimento?

Para Davenport (1998, p.19), o "conhecimento é a informação mais valiosa (...) é valiosa precisamente porque alguém deu à informação um contexto, um significado, uma interpretação (...)”. O conhecimento pode então ser considerado como a informação processada pelos indivíduos. O valor agregado à informação depende dos conhecimentos anteriores desses indivíduos. Assim sendo, adquirimos conhecimento por meio do uso da informação nas nossas ações. Desta forma, o conhecimento não pode ser desvinculado do indivíduo; ele está estritamente relacionado com a percepção do mesmo, que codifica, decodifica, distorce e usa a informação de acordo com suas características pessoais, ou seja, de acordo com seus modelos mentais.

O conceito de conhecimento possui um sentido mais complexo que o de informação. "Conhecer é um processo de compreender e internalizar as informações recebidas, possivelmente combinando-as de forma a gerar mais conhecimento" (Merton apud Gonçalves, 1995, p. 311).

Ao se considerar a inter-relação entre os três elementos e efetuar a análise tendo como foco o presente estudo, podemos inferir que os dados por si só não significam conhecimento útil para a tomada de decisão, constituindo-se apenas o início do processo. $\mathrm{O}$ grande desafio dos tomadores de decisão é o de transformar dados em informação e informação em conhecimento, minimizando as interferências individuais nesse processo de transformação.

\section{TRANSFORMANDO DADOS EM INFORMAÇÕES E INFORMAÇÕES EM CONHECIMENTOS}

Dotar os dados, as informações e os conhecimentos de significados não é um processo tão simples como parece. Características individuais, que formam o modelo mental de cada pessoa, interferem na codificação/decodificação desses elementos, acarretando muitas vezes distorções individuais que poderão ocasionar problemas no processo de comunicação.

Segundo Lago (2001), Pereira \& Fonseca (1997) e Davenport (1998), para amenizar essas distorções, devemos ter consciência de que:

- existem diferenças entre o que queremos dizer e o que realmente dizemos; entre o que dizemos e o que os outros ouvem; entre o que ouvem e o que escutam; entre o que entendem e lembram; entre o que lembram e retransmitem;

- as pessoas só escutam aquilo que querem e como querem, de acordo com suas próprias experiências, paradigmas e pré-julgamentos;

- existem informações que os indivíduos não percebem e não vêem; informações que vêem, e não ligam; informações que vêem, e não entendem ou não decodificam; informações que vêem e usam; informações que procuram; informações que adivinham;

- nosso estado de espírito e humor pode afetar a maneira como lidamos com a informação;

- as abordagens informacionais normalmente privilegiam os atributos racionais, seqüenciais e analíticos da informação e de seu gerenciamento, em detrimento a outros igualmente importantes, 'senão mais', como os relacionados às abordagens intuitivas e não-lineares. 
Nesta mesma direção, Pereira \& Fonseca (1997, p. 226) salientam que:

"A apreensão da informação é uma função cognitiva superior que se processa no âmbito da linguagem. Sempre que quisermos apreender mais informações do contexto em que estamos inseridos, temos que ampliar as nossas habilidades perceptivas, porque o nosso modo de viver nos induz a um estreitamento perceptivo e a uma visão de mundo restrita e fragmentada e que as necessidades das pessoas em relação à informação mudam constantemente porque a percepção, além de ser individual, é contingente".

Assim sendo, o decisor deve ter a consciência de que o maior desafio não é o de obter os dados, as informações e os conhecimentos, mas sim a aceitação de que, no processo de codificação/decodificação, as distorções ocorrem e que existem formas para amenizá-las.

Podemos exemplificar a interferência das pessoas na codificação, decodificação e distorção na transformação do dado em informação e da informação em conhecimento pelo fato a seguir. Diferentes pessoas diante de um mesmo fato tendem a interpretá-lo de acordo com seus modelos mentais, que as levam a percebê-lo de forma diferente. Por exemplo: um carro BMW, último tipo, conversível, zero quilômetro, totalmente destruído em um acidente no qual o motorista bateu em uma árvore centenária derrubando-a pode ser codificado, decodificado e distorcido das seguintes maneiras. Algumas pessoas serão levadas a decodificar as informações baseadas em seus valores materiais: "Logo um carro tão caro! Será que ele está segurado?” Enquanto outras pessoas, com valores humanos mais aguçados, terão seu foco no ser humano: "Será que o acidente resultou em feridos?" Outras pessoas com interesses ecológicos ainda terão suas atenções voltadas ao destino da árvore centenária: "Logo nesta árvore! Não poderia ter sido em uma outra BMW?”.

Estar consciente dessas e de muitas outras interferências nas lides com os dados, as informações e os conhecimentos no processo de tomada de decisões consiste no primeiro passo para amenizá-las.

\section{ALAVANCANDO AS DECISÕES}

No processo de tomada de decisão, é importante ter disponíveis dados, informações e conhecimentos, mas esses normalmente estão dispersos, fragmentados e armazenados na cabeça dos indivíduos e sofrem interferência de seus modelos mentais. Nesse momento, o processo de comunicação e o trabalho em equipe desempenham papéis relevantes para resolver algumas das dificuldades essenciais no processo de tomada de decisão. Pelo processo de comunicação, pode-se buscar o consenso que permitirá prever a adequação dos planos individuais de ação em função do convencimento, e não da imposição ou manipulação. Pelo trabalho em equipe, pode-se conseguir obter o maior número de informações e perspectivas de análise distintas, sendo validada a proposta mais convincente no confronto argumentativo dos demais (Gutierrez, 1999).

Para alavancar a qualidade das decisões organizacionais, sugerimos uma reflexão na melhoria da comunicação e no envolvimento das pessoas na tomada de decisão.

\section{MELHORANDO A COMUNICAÇÃO}

Alguns teóricos da administração, como Davenport (1998), Nonaka \& Takeuchi (1997), Stewart (1998) e Sveiby (1998), apontam um novo direcionamento da comunicação, voltado principalmente às questões relacionadas à transmissão da informação e do conhecimento organizacional (Angeloni \& Fernandes, 1999).

Os conceitos de dado, informação e conhecimento estão estritamente relacionados com sua utilidade no processo decisório e ligados ao conceito de comunicação. O processo de comunicação é uma seqüência de acontecimentos no qual dados, informações e conhecimentos são transmitidos de um emissor para um receptor.

Segundo Davenport (1998), uma das características da informação consiste na dificuldade de sua transferência com absoluta fidelidade, e, sendo o conhecimento a informação dotada de valor, conseqüentemente, a transmissão é ainda mais difícil.

A informação é valiosa precisamente porque alguém deu a ela um contexto, um significado, acrescentou a ela sua própria sabedoria, considerou suas implicações mais amplas, gerando o conhecimento. O conhecimento, consequëntemente, é tácito e difícil de explicitar. "Quem quer que já tenha tentado transferir conhecimento entre pessoas ou grupos sabe como é árdua a tarefa. Os receptores devem não apenas usar a informação, mas também reconhecer que de fato constitui conhecimento". (Nonaka apud Davenport, 1998, p. 19) 


\section{Maria Terezinha Angeloni}

Para melhorar a qualidade da comunicação, o ser humano precisa desenvolver as habilidades de se expressar e de ouvir. Normalmente as pessoas estão predispostas a defender seus pontos de vista, assim, quando um interlocutor está falando, o outro não está atento ao que ele está dizendo, mas já está preparando a argumentação para defender seu ponto de vista, interferindo na qualidade da comunicação. A ação comunicativa realmente ocorre quando as pessoas, livres de autodefesas, buscam chegar a um acordo sobre determinada situação de decisão, ouvindo e respeitando outros pontos de vista. Corroborando esse ponto de vista, Gutierrez (1999, p. 38), "pressupõe que um conjunto de pessoas, com preparação intelectual, informações e interesse em chegar a um acordo, debate todas as alternativas possiveis, até constituir um plano de ação coletivo consensual”. $\mathrm{O}$ autor compreende que esse processo "vai das normas de educação até a ausência de desvios patológicos que possam impedir a percepção do sentido geral de uma discussão, ou a revisão pessoal de comportamentos e conceitos quando confrontados com argumentos distintos".

As pessoas passam assim a contribuir no campo das decisões "quando conseguem, no processo do diálogo, colocar-se no lugar do outro e perceber, a partir desta nova perspectiva, suas razões e interesses" (Piaget apud Gutierrez, 1999, p. 41), tornando-se fundamental destacar a importância da maturidade como elemento essencial na comunicação organizacional para a tomada de decisão.

A decisão é assim considerada como um sistema lingüístico, um processo essencialmente coletivo no qual impera a multirracionalidade, ou anti-racionalidade, preconizada por Sfez (1984), caracterizada pela interferência das diferenças individuais na coleta e interpretação da informação, impossibilitando a existência de apenas uma decisão, "a correta". Se não existe uma única alternativa para determinada situação de decisão, onde fica a racionalidade? Para diminuir as interferências individuais, um dos caminhos sugeridos é o da decisão em equipe.

\section{ENVOLVENDO AS PESSOAS NA DECISÃO}

A tomada de decisão nas organizações vai exigir cada vez mais trabalhos em equipe e maior participação das pessoas. O trabalho em equipe coloca em evidência os procedimentos de diálogo baseados na idéia de que, em uma organização, a comunicação deve ser estimulada visando ao estabelecimento deum pensamento comum (Angeloni, 1992).
O estabelecimento de um pensamento comum consiste em considerar o ponto de vista de cada um, para que as decisões tomadas nas organizações tenham um nível de qualidade superior. $\mathrm{O}$ processo decisório passa então do nível individual para o nível de equipe.

Considerando que nenhuma pessoa detém todas as informações e conhecimentos organizacionais e que nem sempre estas informações e conhecimentos estão explicitados e disponíveis, fazendo com que cada um detenha apenas uma parte deles, a tomada de decisão em equipe é uma forma a ser utilizada para superar as barreiras das informações e conhecimentos parciais.

A tomada de decisão que envolve um maior número de pessoas tende a resultados mais qualificados, aumentando o conhecimento da situação de decisão, amenizando, pela agregação de informações e conhecimentos, as distorções da visão individualizada.

Decisões tomadas por equipes heterogêneas, compostas por mulheres, homens, jovens, idosos, tendem a resultados de maior qualidade. Pessoas com pontos de vistas e experiências diferentes decodificam a situação de decisão também de maneira diferente. Ouvir e tentar compreender essas visões leva ao aprimoramento das decisões. As decisões tomadas em equipes tendem a ser mais sólidas que as tomadas individualmente, apesar de, normalmente, demandarem mais tempo.

Quando falamos em tomadas de decisões e principalmente de tomada de decisão em equipe, não podemos deixar de considerar o papel que exerce a tecnologia.

\section{USANDO A TECNOLOGIA COMO SUPORTE}

A tecnologia exerce um papel essencial tanto na comunicação e armazenamento dos dados, das informações e dos conhecimentos como na integração dos tomadores de decisão. Exerce também enorme potencial para o compartilhamento do conhecimento. De qualquer parte do mundo, o tomador de decisão pode acessar a experiência passada de outras pessoas e aprender com elas (Johnson, 1997). A troca de informações e de conhecimentos e sua qualidade e rapidez estão no coração do sucesso das organizações. Quanto maior a capacidade das tecnologias da informação e da comunicação, maior a capacidade de inter-relacionamentos e a capacidade de aprender e lucrar com o compartilhamento da informação e do conhecimento. 
Ao mesmo tempo em que elas conduzem a um aumento da capacidade de compartilhamento da informação e do conhecimento, possibilitam também o aumento de suas quantidades disponíveis, que é, antes de tudo, um aumento de dados brutos, dos quais apenas uma parte se transforma em informações potenciais, o que significa que apenas pequeno número delas se transformará em informações ou em conhecimento (Lussato, 1991). O aumento constante do volume de informações e conhecimentos tem constituído crescente dificuldade em momentos de decisão. $\mathrm{O}$ executivo do início do século tomava decisões baseado na escassez de informações. Nos dias de hoje, o executivo se depara com uma quantidade crescente de informações disponíveis. Soterrados em um mar de dados, informações e conhecimentos, devem desenvolver habilidades e competências para separar o "joio do trigo", pois, para a informação e o conhecimento serem considerados úteis, devem ser compreendidos e utilizados pelo tomador de decisão.

\section{REPRESENTANDO OS ELEMENTOS INTERVENIENTES NA TOMADA DE DECISÃO}

Compreendendo o que é dado, informação e conhecimento e suas inter-relações com os processos de comunicação e decisão apresentamos, na figura 1, os elementos intervenientes na tomada de decisão, que busca incitar a discussão de que o dado, a informação e o conhecimento devem ser vistos como uma cadeia de agregação de valor e que os mesmos são elementos essenciais à tomada de decisão e que, portanto, não devem ser confinados na cabeça dos indivíduos organizacionais, mas compartilhados mediante um sistema de comunicação bem estabelecido.

Ao se considerar o dado como matéria-prima da informação e a informação, por sua vez, como a matériaprima do conhecimento, de nada adianta a organização dispor de dados, informações e conhecimentos, se nela persistir a cultura de que dados, informações e conhecimentos constituem poder. As informações e os conhecimentos devem circular interna e externamente na organização por meio de um eficiente sistema de comunicação, envolvendo a instalação de uma infraestrutura tecnológica adequada. Só assim a organização disporá de dados, informações e conhecimentos de qualidade e em tempo hábil para dar suporte à tomada de decisão.
FIGURA 1

\section{Elementos intervenientes na tomada de decisão}

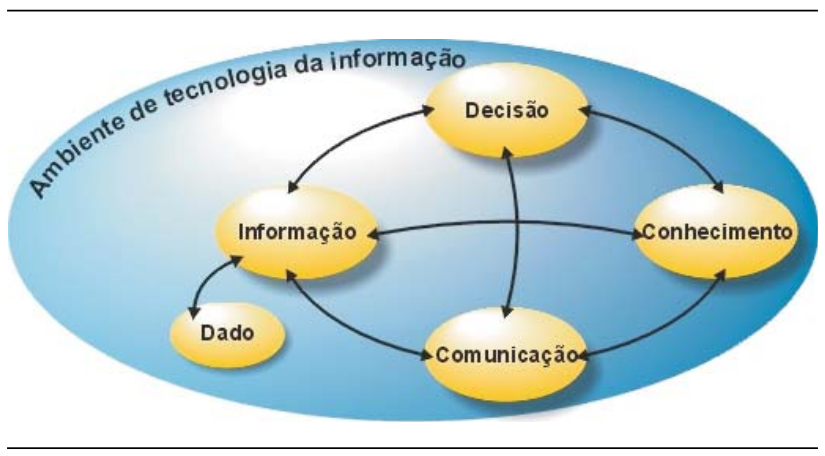

A análise dos elementos intervenientes na tomada de decisão não tem a intenção de finalizar a discussão a respeito da tomada de decisão nas organizações, tendo em vista a sua complexidade. Nesse sentido, faz-se necessária uma reflexão sobre o tema nas palavras de Gutierrez (1999, p. 33):

"Não existe uma fórmula perfeita para a tomada de decisões corretas na empresa. Na organização tradicional, as decisões são tomadas por uma elite decisória que se perpetua no poder através de um amplo processo de alianças, provocando distanciamento dos macrobjetivos e perda de informação. A gestão comunicativa, por sua vez, fundamenta-se na ação comunicativa que consiste na formação discursiva da vontade, pelo debate entre subjetividades intactas, em condições próximas do ideal. Um elemento essencial para este processo de tomada de decisões é a expectativa de um comportamento individual maduro, tanto social quanto moral. $\mathrm{O}$ resultado é um confronto entre a complexidade evitável e inevitável dos modelos tradicional e comunicativo de gestão".

\section{CONSIDERAÇÕES FINAIS}

Um mundo de intensas e rápidas mudanças levou a sociedade e as organizações à Era da Informação e do Conhecimento. Os recursos estratégicos básicos da Era Industrial cedem o lugar de destaque a outros recursos: a informação e o conhecimento, apoiados pela tecnologia.

Passamos assim das ondas que privilegiavam os músculos para as ondas que privilegiam o cérebro, passamos do foco na mão-de-obra para o foco no cérebro-de-obra, da valorização dos bens tangíveis para a valorização dos bens intangíveis e, conseqüentemente, a valorização do ser humano nas organizações, pois a utilização desses elementos depende essencialmente do ser humano educado, competente, envolvido no processo gerencial. 
As tecnologias da informação conduzem a profundas evoluções organizacionais. Elas levam a novas formas de gestão e, por conseqüencia, a novas formas organizacionais. As organizações devem estar preparadas para suportar o crescente volume e rapidez de circulação de informações e conhecimentos, implantando estruturas organizacionais e tecnológicas flexíveis que permitam a circulação das informações e dos conhecimentos, a fim de poder tomar decisões em tempo hábil e se adaptar às mudanças do meio ambiente em que estão inseridas.

Artigo aceito para publicação em 25-11-2002

\section{REFERENCIAS}

ANGELONI, M. T. Technologies de transmissión de l'information et consequences sur le processus des decisions des organizations. Grenoble, France : Mémoire_de DEA. École Superieure des Affaires, 1992.

; FERNANDES, C. B. A comunicação empresarial. Revista de Ciências da Administração, Florianópolis, v. 1, n. 2, ago. 1999.

DAVENPORT, T. H. Ecologia da informação: por que só a tecnologia não basta para o sucesso na era da informação. São Paulo : Futura, 1998.

GONÇALVES, M. A. Os papéis do gerente e a qualidade da informação gerencial. In: ENCONTRO ANUAL DA ASSOCIAÇÃO NACIONAL DOS PROGRAMAS DE PÓS-GRADUAÇÃO EM ADMINISTRAÇÃO, 19., 1995, João Pessoa. Anais... Rio de Janeiro, 1995. v. 1, p. 309-325.

GUTIERREZ, G. L. Gestão comunicativa: maximizando criatividade e racionalidade. Rio de janeiro : Qualitymark, 1999.

JOHNSON, M. Administrando no próximo milênio. São Paulo : Pioneira, 1997.

LAGO, A. P. Comunicação: uma perspectiva abrangente. Disponível em:< http://www.rh.matrix.com.br/cgi-rh/bamco/db.pl>. Acesso em: 15 mar. 2001.

MALHOTRA, Y. What is knowledge management?. Disponivel em: <http://www.brint.com.papers/copint.htm>. 1993.

LUSSATO, B. La théorie de l'empreinte. Paris : ESF, 1991.

NONAKA, I.; TAKEUCHI, H. Criação de conhecimento na empresa: como as empresas japonesas geram a dinâmica da inovação. Rio de janeiro : Campus, 1997.

PEREIRA, M. J. L. B.; FONSECA, J. G. M. Faces da decisão: as mudanças de paradigmas e o poder da decisão.-São Paulo : Makron Books, 1997.

SFEZ, L. Critique de la décision. Paris : Seuil, 1984.

STEWART, Thomas A. Capital Intelectual: a nova vantagem competitiva das empresas. Rio de Janeiro : Campus, 1998.

SVEIBY, K. E. A nova riqueza das organizações: gerenciando e avaliando patrimônios de conhecimento. Rio de janeiro : Campus, 1998. 